\title{
DIREITOS REAES
}

I. Noções geraes, natureza e especies.

II. Elementos comimuns, e differenças existentes entre os direitos reaes e o das oirigaçōes.

III. (aracter fundamental c commum a todos os direitos reaes: faculdade de haver o objecto do direito do poder de quem injustamente o detenha.

\section{I}

\section{Noções geraes, natureza e especies}

Os direitos patrimoniaes conferem, ao respectivo titular, poderes de duas ordens: I. O titular exerce o seu poder directo sobre o objecto, independentemente, da intervenção de outrem.

II. O titular exerce o seu poder, directamente, sobre pessôa certa e determinada, que se obrigou a: dar, fazer ou não fazer alguma cousa.

No primeiro caso, o direito tem por objecto immediato cousa corporea, $\mathrm{da}$ qual o respectivo titular retira as vantagens contidas no seu direito.

No segundo caso, o direito tem por objecto directo um acto ou facto de pessôa determinada, que se obrigou para com o titular.

Elucidam o assumpto os dois exemplos: I. Pedro tem o direito de propriedade sobre uma cousa corporea. Este direito confere-lhe os poderes de usar 
da cousa e de retirar-lhe todas as vantagens e utilidades, que ella é susceptivel de fornecer, sem que seja necessaria a intervenção de outra pessôa, além do titular do direito.

II. Pedro empresta a José a importancia de um conto de réis. Por força deste acto formou-se, a favor de Pedro, contra José, um vinculo de direito pelo qual este se obrigou a entregar áquelle a importancia que lhe fôra emprestada.

Pedro, querendo exercer o seu direito, deverá compelir o devedor a effectuar o pagamento da importancia, ou a praticar o acto ao qual se obrigára. $O$ objecto immediato do direito de Pedro é o acto, que José deve praticar e não a importancia, porque esta só poderá ser recebida, mediante $o$ acto de José.

Os direitos da primeira especie denominam-se direitos reaes, jura in re, porque recahem directamente sobre cousa corporea. Nos direitos da segunda especie descobre a analyse uma natureza pessoal, porque o seu exercicio depende do acto ou facto de outra pessôa, além do respectivo titular. Como estes direitos geram-se de relações, obrigacionaes denominam-se mais propriamente, direitos das obrigações. Esta expressão, além de precisar o instituto, tem a vantagem de evitar a confusão entre estes direitos e outros, que tem a mesma natureza pessoal, mas delles se distinguem por sua origem, permanencia, extensão, seu objecto e effeitos, como: - I os direitos relativos ao estado e capacidade das pessoas (abrangem as faculdades, que constituem a personalidade e denominamse - jura personarum); II os direitos ligados ao titular e que, com elle, se extinguem (assim o usufructo, embora direito real, por ser desmembramento do dominio, tem fim pessoal, por ser instituido intuitu personae; é ligado á pessôa do titular e, com elle extingue); III certos direitos, que devem ser exercidos pessoalmente por seu titular, como o patrio poder, a tutella e outros; IV 
ainda os direitos impenhoraveis pelos credores de um devedor, mesmo nos casos de fallencia ou insolvabilidade, como os alimentos, os bens dotaes, os soldos e vencimentos dos militares, funccionarios civis, as soldadas da gente do mar, os salarios dos guarda-livros e caixeiros dias casas commerciaes e outros. A expressão - direitos pessoaes, applicando-se a diversas ordens de direitos, inclusive ao das obrigações, torna-se ambigua $\mathrm{e}$ seria sempre necessaria uma determinação, para bem exprimir o objecto definido; ao passo que a expressão direito das obrigações - exprime nitidamente o objecto e exclue qualquer confusão. Por isso, esta é a denominação consagrada uniformemente pela doutrina e adoptada pela legislação actual.

O direito real, na sua fórma mais ampla, é o direito de propriedade, que submette a cousa ao poder absoluto e exclusivo de uma pessôa, attribundo-lhe todas as utilidades, que a mesma cousa póde fornecer. Este vasto poder do homem sobre a cousa é complexo e manifestase por tantas formas quantas forem as utilidades, a que a cousa se possa prestar.

Quando o proprietario percebe pessoalmente todas estas utilidades, exerce os elementos activos do seu dominio, utiliza-se economicamente do seu complexo direito; quando, porém desmembra uma parcella do seu vasto poder, em favor de outrem, constitue um direito separado, que conserva a natureza real do тоDo e, por ser constituido sobre cousa alhea, forma um jus in re alienum; ao conjuncto destes desmembramentos do dominio em favor de terceiro, denomina-se - jura in re aliena. O proprietario de um terreno póde utilisar-se delle como bem entender; póde cultival-o e impedir que outrem, nelle, pratique actos contrarios ao seu; entretanto, ex-vi de uma convenção ou de um acto unilateral, póde o proprietario consentir, que seu visinho transite por seu terreno, que nelle 
apascente os seus rebanhos; póde hypothecal-o em garantia de uma obrigação propria ou de outrem. Cada um destes poderes instituidos pelo proprietario, em favor de terceiro, constitue um jus in re, que póde ser exercido, pelo respectivo titular, sem que o dominio ou o direito de propriedade seja destruido. E' certo que a acção do proprietario, sobre a cousa, fica limitada nas proporçôes do jus in re; desapparecendo ou extinguindo-se este, o dominio retoma seus caracteres peculiares - livre, absoluto e exclusivo -, de accordo com a ordem juridica e neces sidades sociaes.

São multiplos os desmembramentos do dominio e é mesmo difficil traçar um limite numerico dos direitos reaes sobre cousa alheia. A acção do proprietario, neste caso, só encontra limite na essencia do direito de propriedade - $o$ jus abutendi-, ou a faculdade de dispor da cousa, porque esta faculdade é da essencia do dominio; retiral-a importaria na alienação do respectivo objecto e consequente extincção do direito. A legislaçã̃o dos povos cultos, por motivos de ordem economica, limita a acção do proprietario, enumerando taxativamente os jura in re aliena.

O nosso Cod. Civ. no art. 674 estatue: "São direitos reaes, além da propriedade:

I. A emphyteuse.

II. As servidões.

III. O usufructo.

IV O uso.

V. A habitação.

VI. As rendas expressamente constituidas sobre immoveis.

VII. O penhor.

VIII. A antichrese.

IX. A hypotheca. 
O Codigo exclue a superficie que, no Direito Romano, era um jus in re - Dig. L. 43, Tit. 18.

Sendo o direito real um poder da pessôa, exercido directamente sobre a cousa corporea; sendo este poder amplo, no caso do dominio ou limitado, nos jura in re aliena e exercendo-se erga omnes, conclue-se que, tanto num, como noutro caso, póde o respectivo titular praticar todos os actos de accordo com o seu direito, excluir do seu exercicio a intervenção de outrem e rehaver o objecto de quem injustamente o detenha.

Reunindo estes elementos essenciaes indicados numa formula synthetica, podemos construir a noção seguinte:- "DIREITo REAL" é o que legalmente submette, completa ou parcialmente, á vontade da pessôa a cousa corporea e segue-a em poder de quem quer que, injustamente a detenha"

Dos elementos indicados e da noção formulada con. clue-se que o direito real é absoluto, porque oppõem-se erga omnes e, por isso, todos, que convivem com o titular do direito, são obrigados a respeitar-lhe o exercicio e cumprem esta obrigação, não praticando acto algum, que perturbe o referido exercicio.

Da comprehensão da obrigação decorrente do direito real e do modo por que ella é cumprida, os jurisconsultos a denominam - Obrigação geral e negativa.

E' GERAL, porque comprehende todas as pessoas, incumbe a toda a massa social. E' NEGATIVA, porque cumprese por inacção, não praticando acto algum que perturbe o livre exercicio do direito do respectivo titular. Examinando detidamente, deste ponto de vista, descobre a analyse, no direito real, uma relação obrigacional, na qual é o titular o credor e a massa social o devedor, na relação.

Impressionados com esta observação alguns civilistas francezes foram levados a negar a distincção entre direitos reaes e o das obrigações. 
Neste sentido Planiol conclúe que o "direito real é uma relação juridica estabelecida entre uma pessoa, como sujeito activo, e a massa social, como sujeito passivo" Droit Civ. vol. 1, n. ${ }^{\circ} 2160$. Desenvolvendo a sua formula observa o eminente autor: "Esta relação é de ordem obrigatoria, isto é, tem a mesmá natureza das obrigações propriamente ditas" E' fórá de duvida que o direito real, como qualquer outro, manifesta-se na vida social sob a forma de uma relação obrigacional; parece-nos, entretanto, exaggerada a importancia dada por aquelles autores, á obrigação geral e negativa a ponto de obliterar a distincção entre direitos reaes e o das obrigações, e de fazer desapparecer a noção tradicional. A obrigação geral e negativa decorrente do direito real não tem a natureza e energia do vinculo juridico, que forma o direito de obrigação.

Aquella obrigação geral e negativa exprime apenas o principio superior de ordem social e moral, segundo o qual a ninguem é licito invadir a esphera de acção do seu semelhante, nem perturbar-lhe o legitimo exercicio da sua liberdade. Transformar, porém, este principio social e moral num vinculum juris parece que importaria em retirar ao vocabulo OBRIGAÇÃo o seu verdadeiro sentido technico, dando-lhe uma outra significação, que produziria perniciosos effeitos, não só no direito de fundo, como no direito processual. A obrigação de reparar o damno no direito real emerge do acto ou facto violador do direito e não se funda em vinculo algum anterior. A noção formulada por alguns autores francezes e defendida por Planiol conduz logicamente á obliteração da fundamental distincção entre direitos reaes e pessoaes; entretanto, sobre esta distincção, o proprio Planiol, Dir. Civil. 1 n. ${ }^{\circ} 2153 ; 3 .^{a}$ edição, ensina: - "A distinç̧ão entre direitos reaes e o das obrigações é uma das noções essenciaes do direito e uma das mais difficeis de adquirir, no começo dos estudos; entretanto, é necessario insistir nella, consagrando a cada uma destas 
duas categorias de direitos o possivel desenvolvimento. Todo o cuidado empregado na escolha das formulas e definições, todo o methodo applicado á exposição desta theoria, lhe não apagará as difficuldades. Tocamos, neste ponto, as noções mais geraes, mais abstractas e, por isso mesmo. mais difficeis do direito"

A definição de direito real formulada por Planiol é tão vaga, tão imprecisa, que se applica a todos os direitos denominados absolutos, como a vida, a honra, a saude, aos quaes corresponde uma obrigação geral e negativa, confundindo-os com os direitos reaes, cuja distinç̧ão é essencial, como bem pondera Planiol nas passagens transcriptas.

Parece que estes autores, partindo de um principio verdadeiro, chegaram a consequencias falsas, por haverem exaggerado o caracter juridico da obrigação geral e nega . tiva decorrente do direito real, entretanto, elles prestaram importante serviço á sciencia, evidenciando a improcedencia da doutrina que considera o direito real - uma relação directa entre pessôa e cousa.

Esta doutrina apresenta como caracter essencial do direito real a creação de uma relação juridica entre pessôa e cousa.

De qualquer ponto de vista é falsa esta noção. Na forma, parece exprimir que na relação de direito real não ha intermediario algum entre a pessoa - titular - e a cousa - objecto do direito. $O$ proprietario de uma casa póde habital-a, o dono de um terreno cultiva-o, o usufructuario de uma cousa alheia, percebe-lhe os fructos. Todos estes actos praticam-se, independentemente da intervenção de outrem. Esta analyse do direito real, porém, evidencia sua apparencia apenas, dá uma idéa, que satisfaz ás necessidades praticas e parece exprimir a figura concreta do direito real; pois apresenta o titular exercendo directamente o seu poder sobre a cousa objecto do dominio ou do usufructo. 
Na forma é falsa esta noção, porque a pretensa relação indicada ou, melhor, o phenomeno observado é apenas o exercicio ou manifestação exterior do direito e não o proprio direito. Este exercicio ou manifestação exterior do direito constitue um estado:de facto, que tem seu nome technico - Posse.

Se o proprietario tem a cousa sob o seu poder; se, sobre ella, pratica actos de senhor; se a possue, emfim, é, porque, em regra, tem direito de o fazer.

Se exerce constantemente taes actos, é em virtude de um direito pre-existente. A manifestação do seu poder sobre a cousa é o exercicio do seu direito e não o proprio direito; pois este tem dois momentos bem distinctos - $o$ principio theorico, que define a garante a faculdade e $o$ facto ou exercicio da mesma faculdade.

No fundo é tambem falsa a noção, porque uma relação de direito, sendo de ordem moral, não póde existir entre a - pessoa - ser intelligente e livre e a - cousa objecto inanimado. $O$ direito existe para disciplinar as relações dos homens em sociedade; logo consiste numa "relação entre pessoas" Sobre esta verdade axiomatica repousa toda a construcção juridica. A ampla comprehensão deste axioma concorreu, talvez, para a citada formula de Planiol, como parece evidenciar o seguinte: - Segundo este eminente civilista o direito real deve ser concebido sob a fórma de uma relação obrigacional, na qual o sujeito activo é simples e representado por pessoa determinada natural ou juridica, ao passo que o sujeito passivo é indeterminado e numericamente illimitado; pois comprehende a massa social ou todas as pessoas que convivem com o titular do direito. O papel inactivo e apagado imposta á massa social faz com que se não perceba logo a natureza da relaação da qual ella é parte. Como se não exige da sociedade senẫo abstenção, que é a normalidade da vida, ella desapparece na relação, vendo-se, então, sómente, o su- 
jeito activo em face do seu direito. Deste contacto directo decorreu a noção vulgar de relação entre pessoa e cousa. Examinando bem a relação, continúa Planiol, verificase que é tão real o sujeito activo - pessoa - como o sujeito passivo - sociedade - obrigado a respeitar a acção legitima do titular do direito, como ensina Rougon. Les Regles du Droit, pag. 54, n. 26, 2. ${ }^{\circ}$ - “E' necessario considerar os direitos reaes como formados de um feixe de deveres passivos impostos á totalidade dos homens, e cada fibra deste feixe tem a natureza de uma obrigação, no sentido especial do vocabulo" - A verdade expressa por esta figura, pondera ainda o eminente civilista, torna-se manifesta, pela violaçã̉o do direito da qual resulta o vin. culo obrigacional imposto á sociedade, porque o violador é condemnado a indemnisar o mal causado; e esta condemnação se não comprehenderia, se não fôra a obrigação preexistente.

Dos proprios termos e argumentos do sabio Planiol evidencia-se a procedencia da nossa affirmação - 0 QUE FAZ SURGIR A OBRIGAÇÃO, NO DIREITO REAL É O ACTO OU FACTO VIOLADOR DO DIREITO. - Antes da violação do direito real era este amparado pelo principio superior de ordem social e moral - que a ninguem é licito perturbar a legitima acção dos seus semelhantes.

Sendo este principio indispensavel á existencia social, justifica-se a coacção imposta ao seu transgressor.

Pela infraç̧ão deste principio superior e consequente violação do direito, constituiu-se o infractor na obrigação de reparar o mal causado; e, como o damno localisou-se no direito de uma determinada pessaa, a esta deve ser feita a respectiva indemnisação.

Esta obrigação, porém, surgiu do acto ou facto viola. dor do direito e lhe não era preexistente, como pensa Pla. niol. 
As affinidades observadas entre os direitos reaes e o das obrigações evidenciam a origem commum, como partes de um ToDo; não obliteram porém, as distincções entre elles existentes.

\section{II}

\section{Caracteres communs e differenças existentes entre os direitos reaes e o das obrigações}

Sendo o direito uma relação entre pessôas, segue-se que tanto os direitos reaes como o das obrigações devem revestir este cunho geral e o elemento constitutivo de ambas é commum — "norma reguladora da conducta dos homens em sociedade" Ainda mais: pertencem ambas á grande classe dos "direitos patrimoniaes"

Estas homogeneidades, porém não obliteram os caracteristicos peculiares a uma e a outra especie de direitos e nem apagam as differenças. entre elles, existentes.

Differem por caracteres especificos fundados: $1 .^{\circ}$ na determinação; $2 .^{\circ}$ na natureza do objecto; $3 .^{\circ}$ na determinação do sujeito passivo; $4 .^{\circ}$ na comprehensão, natureża e effeitos da obrigação.

Além destes caracteres de ordem theorica, outros de caractér pratico, mais accentuam ainda a distincção entre os direitos reaes e o das obrigações.

1. Determinação do objecto. - Sendo o direito real um jus in re, um direito sobre cousa corporea, só poderá recahir sobre objecto individualmente determinado. Não hạ poder possivel, sobre cousa corporea, emquanto não fôr esta determinada na sua individualidade, porque, só- 
mente neste caso poderá o respectivo titular exercer os poderes contidos no seu direito - auferir as utilidades da cousa e reivindical-a do poder de quem, injustamente, a detiver.

O direito de obrigação pode ter por objecto uma prestação consistente na entrega de uma cousa, sómente determinada em especie.

Exemplo - Um commerciante de cereaes vendeu a um freguez dez saccos de trigo de uma certa qualidade e peso de entre os muitos que tem em seu armazem. $0 \mathrm{com}$ prador somente se tornará proprietario, desde o momento em que forem determinados e entregues os saccos vendidos.

Entretanto, desde o dia em que houver contractado a compra, adquire, contra o vendedor o direito a uma cousa, somente determinada em seu genero, e póde tornar effectivo o seu direito, coagindo o vendedor a dar o objecto vendido, mediante a determinação feita de accordo com as clausulas contractuaes.

$2 .^{\circ}$ O objecto do direito real é sempre uma cousa corporea. $O$ direito de obrigação recahe directamente sobre acto ou facto da pessoa determinadamente obrigada na relaçấo.

3. A relação de direito de obrigação existe sempre contra pesșôa certa se ha muitos devedores, são estes limitadamente determinados, A relação de direito real abrange, indeterminadamente, todos que convivem com o titular do direito; pois consiste numa obrigação, qu: envolve toda a massa social. Póde exprimir-se esta differença pela formula -0 direito de obrigação é relativo, porque oppóe-se a certas pessoas : preestabelecidas na relação obrigacional. O direito real é absoluto, por. que oppõe-se a todos indeterminadamente. 
4..$^{\circ}$ O direito real, concebido como relaçáo de obrigação universal, só impõe abstenção. Nada fazer que possa prejudicar o direito do titular.

Muito mais energico é o vinculo gerado pelo direito de obrigação, porque impõe ao devedor uma prestação, em regra, um acto a praticar.

Quando a relação obrigacional impóe ao devedor uma abstenção, esta ainda differe profundamento da abstenção geral e negativa decorrente do direito real. Esta não diminue nem restringe os direitos das outras pessoas; pois apenas se lhes ordena que não perturbem o exercicio do direito do respectivo titular. Exige-se, emfim, a normalidade nas relações da vida social, que é a suprema aspiração do direito. A abstenção imposta pela relação obrigacional diminue o patrimonio do devedor e restringe-lhe os direitos, porque obrigou-se para com o credor a não fazer alguma cousa que, pelo direito commum, podia fazer se não fôra a relação obrigacional estabelecida.

A existencia de um direito de obrigação constitue sempre um encargo especial ao devedor, uma diminuição do seu patrimonio; pois a abstenção, devendo outorgar vantagem ao credor, ha de ter valor economico, A absten. ção universal exigida pelos direitos reaes, para assegurar o respeito ás pessôas e aos bens, não constitue encargo, nem diminue o patrimonio de ninguem. E' o estado normal dos direitos.

Do ponto die vista pratico ainda distinguem-se os direitos reaes do das obrigações.

I. Examinados os elementos constitutivos dos diversos direitos, tendo em vista a lesão possivel, verificase que o direito das obrigações differe de todos os outros direitos. A relação obrigacional suppõe, essencialmente, uma pessôa ebrigada, cujo acto' ou facto é o objecto especial directo do direito; este será lesado se a pessôa obrigada não cumprir a obrigaçãão contrahida e somente 
desta pessôa - devedor - poderá partir directamente a lesão. Os direitos reaes e os que não exigem uma pessôa determinadamente obrigada, podem ser lesados por qualquer pessôa extranha á relação.

Estas considerações evidenciam que o violador de um direito obrigacional é conhecido, mesmo antes da lesão, por ser elemento essencial da relação.

Nos direitos reaes, o violador se torna conhecido pela lesão.

Se elle se transforma em devedor da indemnisação é pelo facto da lesão e não por uma relação preexistente da qual elle seja ou fosse parte expressa.

II. Do ponto de vista da defesa, verifica-se que o direito das obrigações' é de existencia transitoria e delle se não póde usar sem extinguil-o. Os direitos reaes são permanentes e reaffirmam-se de continuo pelo proprio uso.

$A$ acção pessoal protectora do direito obrigacional tem por fim conseguir que o devedor seja condemnado a executar a prestação devida.

Isto conduz necessariamente á extincção do direito, que servia de fundamento á acção.

De facto, executada a prestação, dissolveu-se o vinculo obrigacional e, com elle, extinguiu-se o direito exis. tente.

A acção real tem por fim a permanencia do direito. Se é regado, pede-se que seja declarado; se é ameaçado, requere-se a cessação da ameaça; se é violado, exige-se o seu restabelecimento. Em qualquer dos tres casos a acção tem por fim o equilibrio do direito ou sua permanencia.

III. Do ponto de vista numerico ainda distinguem-se os direitos reaes do das obrigações.

Circunscrevem-se a um numero relativamente pequeno os direitos reaes; são mesmo taxativamente estabelecidos e enumerados pelas legislações positivas. 
Multiplas e indeterminaveis são as formas que podem revestir os actos, factos e abstenções a que os homens se obrigam livremente e nenhuma legislação pretendeu ainda fixar-lhes o numero. Ao contrario, estes actos e factos, se vão multiplicando de continuo na razão directa da cultura humana.

Os caracteres typicos, de ordem theorica e pratica, apresentados, parecem sufficientes para bem accentuar a distincção entre os direitos reaes e o das obrigações.

\section{III}

Caracter fundamental e commum a todos os direitos reaes: Poder de rehaver a cousa, objecto do direito, de quem injustamente a detiver.

Da ultima parte da definição decorre este caracter fundamental e commum a todos os direitos reaes.

Os caracteres - exercicio do poder directo sobre a cousa, nem sempre apparecem nos direitos reaes, ao passo que este terceiro caracter é constante e commum a todos. Os jura in re alinea podem ser classificados em dois grupos, considerando-se: - o fim, natureza e ordem de utilidades outhorgadas. Em regra os jura in re têm por fim collocar a cousa corporea sob o poder directo do titular e conferir-lhe todas ou algumas vantagens materiaes da propriedade. Ha entretanto tres direitos reaes sobre cousa alheia, que constituem excepção áquella regra e formam um grupo especial. Os direitos que constituem este grupo tem por fim garantir a execução de uma obrigação da qual dependem, como accessorios e, pela funcção que exercem de garantir a execução da obrigação, denominam-se: direitos reaes de garantia. Esta denominação é consagrada pelo Codigo Civil, Livro II, Tit. III, Capitulo VI. 
Constituem este grupo: - o penhor, a antichrese e a hypotheca.

Nenhum delles confere, ao titular, vantagens materiaes directamente sobre a cousa. Embora o caracter commum - de accessorios - differem comtudo quanto a extensáo, e ao modo por que se exercem.

No penhor - o devedor ou um terceiro entrega ao credor uma cousa movel, com o fim de sujeital-a ao pagamento da divida. Nenhum direito aos fructos ou rendimento é conferido ao credor, que só tem a guarda da cousa e, para tornar effectivo este poder, a lei conferelhe a faculdade de invocar os interdictos possessorios.

$\mathrm{Na}$ antichrese - o devedor ou um terceiro entrega ao credor um immovel, transferindo-lhe o direito de perceber-lhe os fructos, para imputal-os nos juros da divida e, excepcionalmente na sua amortização. No primeiro existe - permuta de uso ou de vantaçens, como exprime o proprio vociabulo antichrese; no segundo, o phenomeno reveste a figura exterior de um pagamento ou extinç̧ão gradual da divida.

O penhor e antichrese têm de commum que, em ambos, desloca-se a cousa do poder do seu dono. A antichrese, porém, é mais ampla, pois confere direitos á percepção de fructos e o penhor sómente á guarda da cousa.

$\mathrm{Na}$ hypotheca - o devedor ou terceiro, por uma con. venção, submette o immovel ao pagamento de uma divida, sem retiral-o da posse do seu dono.

Nenhuma vantagem material da propriedade, nenhum poder directo e actual sobre a cousa, confere a hypotheca. Caso, porém, o devedor não execute a obrigação, apparecem a efficacia e o caracter real da hypotheca, e esta natureza real manifesta-se exclusivamente pelo direito de sequella, que consiste na faculdade de rehaver a cousa 
hypothecada do poder de quem a detiver, ainda mesmo a titulo de proprietario. Verifica-se que este caracteristico é commum a todos os direitos reaes, ainda mesmo á hypotheca e por isso é "caracter fundamental dos direitos reaes"

Estas considerações evidenciam a improcedencia da opinião de alguns civilistas, que negam á hypotheca a natureza de direito real, por não conferir ao respectivo titular - poder directo actual sobre a cousa e vantagens materiaes da propriedade. Fundados neste conceito, collocam erradamente a hypotheca no - direito das obrigações.

\section{Dr. líanoel Pacheco Prates. Professor de Direito Civil.}

